\title{
Using Video Media to Enhance Conceptual Learning in an Undergraduate Thermodynamics Course
}

\section{Dr. James P Abulencia, Manhattan College \\ Dr. Margot A Vigeant, Bucknell University}

Dr. Margot Vigeant is associate dean of engineering and associate professor of chemical engineering at Bucknell University. Her technical interests include engineering pedagogy, food science and engineering, and modeling flow and diffusion.

\section{Dr. David L. Silverstein, University of Kentucky}

Dr. David L. Silverstein is the PJC engineering professor of Chemical Engineering at the University of Kentucky and director of the College of Engineering's Extended Campus Programs in Paducah, Kentucky where he has taught for 13 years. His Ph.D. and M.S. studies in Chemical Engineering were completed at Vanderbilt University, and his B.S. in Chemical Engineering at the University of Alabama. Dr. Silverstein's research interests include conceptual learning tools and training. He has particular interests in faculty development. He is the recipient of several ASEE awards, including the Fahein award for young faculty teaching and educational scholarship, the Corcoran award for best article in the journal Chemical Engineering Education (twice), and the Martin award for best paper in the Chemical Engineering Division at the ASEE Annual Meeting. 


\title{
Using Video Media to Enhance Conceptual Learning in an Undergraduate Thermodynamics Course
}

\begin{abstract}
This project addresses the need for changing undergraduate chemical engineering education to take advantage of skills possessed by a media savvy generation of students. More specifically, millennials communicate through a broad range of technology from texting to mobile video conferencing. This project aims to leverage these skills, more specifically their affinity to watching online videos, to enhance conceptual learning in an introductory thermodynamics course.

To this end, the collaborative team from Manhattan College, Bucknell University, and the University of Kentucky will have students: 1) develop an instructional video that teaches a concept in thermodynamics using common metaphors, and 2) watch a similarly constructed instructional video developed by peers. A thermodynamics concept inventory administered pre and post-treatment will measure studentsôconceptual learning. The first year implementation of this three year project tasked students to generate a video that teaches a thermodynamic concept. This activity centers on autodidactic learning, where students that are required to teach a topic must master it. The mean scores from all of the institutions revealed that there was no significant difference between the group who generated these teaching videos, and control. This may be attributed to the fact that students were tasked to generate a video on only one topic, rather than several covering a broad range. The second year of implementation tasks students to watch videos from all of the topics, and is the current focus of the collaboration.
\end{abstract}




\section{Introduction}

Todayôs generation of students, often called ñmillennialsò or ñGeneration Yò, have been exposed to technology most of their lives. With the ubiquity of mobile devices and internet access, two things are apparent: 1) the millennials communicate differently (e.g. email and text) compared to previous generations, and 2) information is easily attained (i.e. via the internet). Because of this environment, the learning needs of this generation of students will be different compared to students in the past.

In this project, we seek to leverage video to improve conceptual understanding in an introductory chemical engineering thermodynamics course. The project is administered over three years, with four treatment groups. These are:

\section{Year 0 ï Control}

Matriculated students in an introductory thermodynamics course participate in the traditional manner, with no additional projects.

\section{Year 1 ï Video Generation}

Students taking the course will be assigned a topic in thermodynamics from a prescribed list, and generate a 3-5 minute video that teaches that topic using common metaphors.

\section{Year 2 ï Video Viewing}

Students will be asked to view selected videos generated from Year 1. These videos will encompass all of the topics addressed in the Thermodynamics Concept inventory.

\section{Year 3 ï Video Generation and Viewing}

Students will be asked to generate a 3-5 minute video that teaches a prescribed using common metaphors AND watch selected videos generated from Year 1 of the study.

A Thermodynamics Concept Inventory administered during the first week and last week of the semester will be used to evaluate student learning. Details of this instrument can be found in the Methods section.

This paper presents results obtained after Year 1 of the study. Since students will have to teach a concept in their video, it is expected that they will have to master the concept in order to effectively do so. Thus, students participating in this assignment will be exposed to elements of autodidactic (i.e. students have to teach themselves) and cooperative learning (i.e. students have to consider how to be communicate to their peers). 


\section{Methods}

Chemical engineering students that were matriculated in the introductory thermodynamics course from the participating institutions were tasked to film a video that depicts that concept into simple, everyday language. The topic of the video was assigned to each group of four or five students from a prescribed list, eight weeks prior to the conclusion of the semester. Each group met with their professors to discuss their idea prior to filming. After approval, the groups were provided equipment to film and edit their work. Students were provided minimal guidance during the video production phase. Final submissions were assessed on how technically sound and creative their metaphors were, and translated into their course grade. Videos that were judged to be technically correct were saved for the Year 2 studies.

Assessment of the studentô conceptual understanding will be documented through the use of the Thermodynamics Concept Inventory developed by Vigeant et al, which is a product of prior NSF support (DUE\# 0717536). This instrument is comprise of 36 multiple-choice questions that students can take online for ease of administration and data collection. The Concept Inventory was administered during the first and last week of the semester for each year of the study for each of the treatment groups (i.e. Year 0 and Year 1).

\section{Results}

The objective in Year 1 of this study is to demonstrate improvement in conceptual learning in students who have developed an instructional video teaching a thermodynamics concept that was taught in their introductory thermodynamic course. Students from three different institutions were tasked to generate a video from a prescribed list of topics during the second half of their semester. At the conclusion of the course, they took a Thermodynamics Concept Inventory. Table 1 shows the collective Year 1 data from the three participating institutions versus control (i.e. students who did not generate videos in Year ñò). Both treatment groups represent student scores measured at the conclusion of the thermodynamics course at each institution.

Table 1: Collective Final Mean Scores of Each Treatment Group

\begin{tabular}{|l|c|c|c|}
\hline Intervention & Mean Score & $\mathrm{n}$ & Standard Deviation \\
\hline Year 0 - Control & 23.72 & 58 & 4.37 \\
\hline $\begin{array}{l}\text { Year 1 ï Video } \\
\text { Generation }\end{array}$ & 22.51 & 65 & 6.66 \\
\hline
\end{tabular}

Although there is a slight decrease in score with the group generating videos compared to those that did not, statistical analysis using a oneway ANOVA indicated that there was no significant difference between the two groups. This result contradicts our objective, namely that tasking students to generate a video that teaches a thermodynamics concept (Year 1) did not increase their conceptual understanding of the subject compared to a course where they were not given 
that assignment (Year 0). One possible explanation of this unexpected outcome is that students were tasked on only one topic in thermodynamics, while the Concept Inventory assessed their knowledge in five topics. Thus, it is not unreasonable to assert that having students perform the assignment on a single topic is not sufficient to have a broad mastery of all the concepts.

Correlating participants (and the topics they were assigned) to the relevant questions on the Concept Inventory would have been illuminating to see any improvement in conceptual learning, but impossible to execute after the blind data was already tallied. This will be done during Year 3 of the study, where students will be tasked to both generate a video (i.e. Year 1) and watch videos from all topics (i.e. Year 2).

It is noteworthy to mention that students, whether they generated a video (Year 1) or not (Year 0), demonstrated significant improvement between the beginning of the course and end of the course (data not shown). Thus, the time required for students to execute this assignment, which is essentially an add-on from the traditional Year 0 course, does not detract them from learning the concepts as a whole.

\section{Conclusions}

The first year of this study attempted to demonstrate the improvement in conceptual learning in students who have developed an instructional video teaching a thermodynamics concept that was taught in their introductory thermodynamic course. Students in Year 1 of the study did not show significant improvement compared to control (Year 0), indicating that the assigned task has no effect on their conceptual learning. This may be attributed to the fact that students were only responsible to generate videos on only one topic, versus the five they were evaluated in the Thermodynamics Concept Inventory. Regardless, students in both Year 0 and Year 1 of the study demonstrated improvement between the beginning of the course and the end.

The project is supported by the National Science Foundation (NSF) Transforming Undergraduate Education in Science, Technology, Engineering and Mathematics (TUES). 